\title{
The new National Atlas of Hungary - volume Society
}

\author{
Gábor Gercsák $1^{\text {aa }}$, Károly Kocsis $2^{\text {b }}$, Zsombor Nemerkényi $3^{\text {b }}$, László Zentai $4^{\text {a,* }}$
}

${ }^{a}$ ELTE Eötvös Loránd University, Institute of Cartography and Geoinformatics, Budapest, Hungary, 1st Author gercsak@map.elte.hu,4th Author - lzentai@caesar.elte.hu

${ }^{b}$ Eötvös Loránd Research Network, Research Centre for Astronomy and Earth Sciences, Geographical Institute, Budapest, Hungary, 2nd Author - kocsis.karoly@csfk.org,3rd Author - nemerkenyi.zsombor@csfk.org

* Corresponding author

\begin{abstract}
:
The current volume, National Atlas of Hungary - Society, is Part 3 of the series. It presents the special world of Hungarian society and, according to the availability of data, also that of the Carpatho-Pannonian Area. By combining the tools of statistics, geography and cartography, the maps present the spatial structure accompanied by numerous graphs, photos, texts and infographics.

The present volume of the National Atlas, Society, contributes to a much deeper understanding of processes and a better understanding of the relationships between phenomena through the presentation of the spatial diversity of demographic and social processes in historical perspective. This is a significant record of the period also showing the challenges that Hungarian society faces at the end of the second decade of the 21st century. This addition to the National Atlas of Hungary - with its extensive body of knowledge presented in this work - is an important document of great benefit not only to geographers but also to historians, economists, politicians, and all other interested parties.
\end{abstract}

Keywords: National atlas, Thematic maps, Hungary

\section{Introduction}

The new edition of the National Atlas of Hungary (MNA) in four volumes and in two languages has been a great undertaking of Hungarian geographers, cartographers and numerous other scientists. This immense project has been coordinated by the Geographical Institute of the Research Centre for Astronomy and Earth Sciences. The National Atlas volumes aim to present the dynamic spatial structure of nature, society and the economy not merely for Hungary, but wherever the required data are available, for the Carpatho-Pannonian Area. The National Atlas - in addition to its impressive printed form - has been published also in digital version (e-MNA) in Hungarian and English in favour of keeping relations with the broader public and meeting the requirements of the time (up-tothe-minute information enhanced with interactive tools and contact with the wider public is ensured by the digital version available at www.nationalatlas.hu). The traditional paper-based edition covers and will cover the most important topics in four volumes (The Hungarian State and its Place in the World; Natural Environment; Society; Economy) and in representative quality.

The first volume of this immense work, Natural Environment, which is Part 2 out of the four volumes, was published both in Hungarian and English in 2018 (Kocsis et al 2019). The English language edition, which was the outcome of wide ranging professional collaboration, received international interest (e.g. Jordan 2019) including the most prestigious international recognition, when the International Cartographic Association held its biennial International Cartographic Conference in Tokyo, in 2019.
This volume was found best from the submitted more than forty atlases released between 2017 and 2019, and it received the title, ICA International Cartographic Exhibition Award Winner (https://icaci.org/map-awards/).

\section{Editorial policy for the new edition of the National Atlas of Hungary}

Preparations of the second edition were started under the coordination of the Geographical Institute of the MTA Research Centre for Astronomy and Earth Sciences (CSFK) of the Hungarian Academy of Sciences in 2013. It is a unique novelty of that the new edition of the National Atlas of Hungary presents maps and information also for the entire Carpathian Basin and its wider neighbourhood (the Carpatho-Pannonian Area), thus covering a territory of some half a million $\mathrm{km}^{2}$ and 34 thousand settlements in twelve countries.

It is to be noted that in the National Atlas, we strictly distinguish the terms 'Pannonian Basin' and 'Carpathian Basin', which are frequently believed to be synonyms. While on the one hand, the Pannonian Basin is a geographical and natural phenomenon, meaning the actual basin between the Alps, the Carpathians and the Dinarides, on the other hand, the Carpathian Basin (without irredentist connotations), frequently used in colloquial Hungarian, covers the historical-cultural homeland, the autochthonous settlement area of Hungarians, in fact, the historical territory of the State.

In addition to the conventional (print) version, for the internet-based National Atlas, interactive analysis and searchability will be enabled; in line with contemporary technical expectations, we wish to build an interactive 
digital national geo-information system and upload the National Atlas content on it. In order to provide foreign readers with authentic information of international standards, in addition to the Hungarian version, it is essential to publish the English translation (with the involvement of native English speakers), as well as the Hungarian original, of the four volumes of the National Atlas and to make them available online.

For the sake of user-friendliness, each chapter of a volume has its own colour, which appears on the margins of pages, in subtitles, as well as in references to non-verbal information. Unlike in strictly academic publications, however in the same way as in other national atlases, the chapters only give the authors' names. Their particulars (scholarly rank, position, primary employer's name and town) are specified at the end of each volume (Authors, Bibliography and Sources). Due to the nature of the genre, we do not include any footnotes or references to any literature. Therefore, all the sources for the texts, for compiling figures, the list of further readings, and names of photographers are to be found in the Authors, Bibliography and Sources section on eleven pages. Due to these reasons (and occasionally space limitations), nonverbal sources (i.e. maps, tables, graphs, diagrams and photos) that enrich the topics do not feature the names of their authors or their origins. Titles of these vital components of the National Atlas are included in the lists of figures, tables and pictures, offering help in focused searching.

In the printed version of the National Atlas, two-page maps accompanied by detailed information have a special significance. They are not always placed next to the text they refer to because they have to be on facing pages so that their middle section should be equally readable. In addition to these illustrations, highlighted in the relevant chapter's colour, text boxes explaining interesting professional terms, ideas or phenomena (often containing their own graphs and other visuals) add content and help the reader use the National Atlas.

Each volume starts with a brief chapter called Hungary at a glance, overviewing the country's particulars. The maps included introduce the administrative division of Hungary in the current year, as well as the general geographical features, i.e. the topography, hydrography and the settlement and transport network of the CarpathoPannonian Area.

In the English versions, geographical names (e.g. topographic, hydrographic and settlement names) are given in English in the first place, or when that does not exist, in the given country's official language. In regions where the proportion of national-ethnic minorities is over $10 \%$, geographical names are given also in the minority language, using ethnonyms both in the maps and in the texts.

The two former Hungarian national atlases were published in characteristic times of the age. The first one (issued in 1967) presented Hungary when the socialist state and economy were consolidated. The second one (produced in 1989) documented Hungary in the last year of the communist state, just before the democratic transition from socialism to market economy, and was ceremoniously presented at the 14th International Cartographic
Conference of the ICA held in Budapest. The maps and their accompanying descriptions in the present and forthcoming volumes of the third edition illustrate the modern and market-oriented Hungary in a completely new political and economic environment. It is almost unparalleled that a country has produced three national atlases within just a bit more than fifty years. This fact demonstrates that the Hungarian community of cartographers, geographers and related sciences has always considered it a national and professional mission to cultivate the image of the country at home and abroad too.

\section{National Atlas of Hungary - Society}

The current 194-page atlas (Figure 1) of a four-volume project is planned to come out in May 2021. Similarly to the previous undertaking, this volume is the outcome of wide-ranging professional collaboration: 17 editors, 42 authors, 87 map authors, and several dozen cartographers, professional and language proofreaders, translators have made their valuable contributions to it.

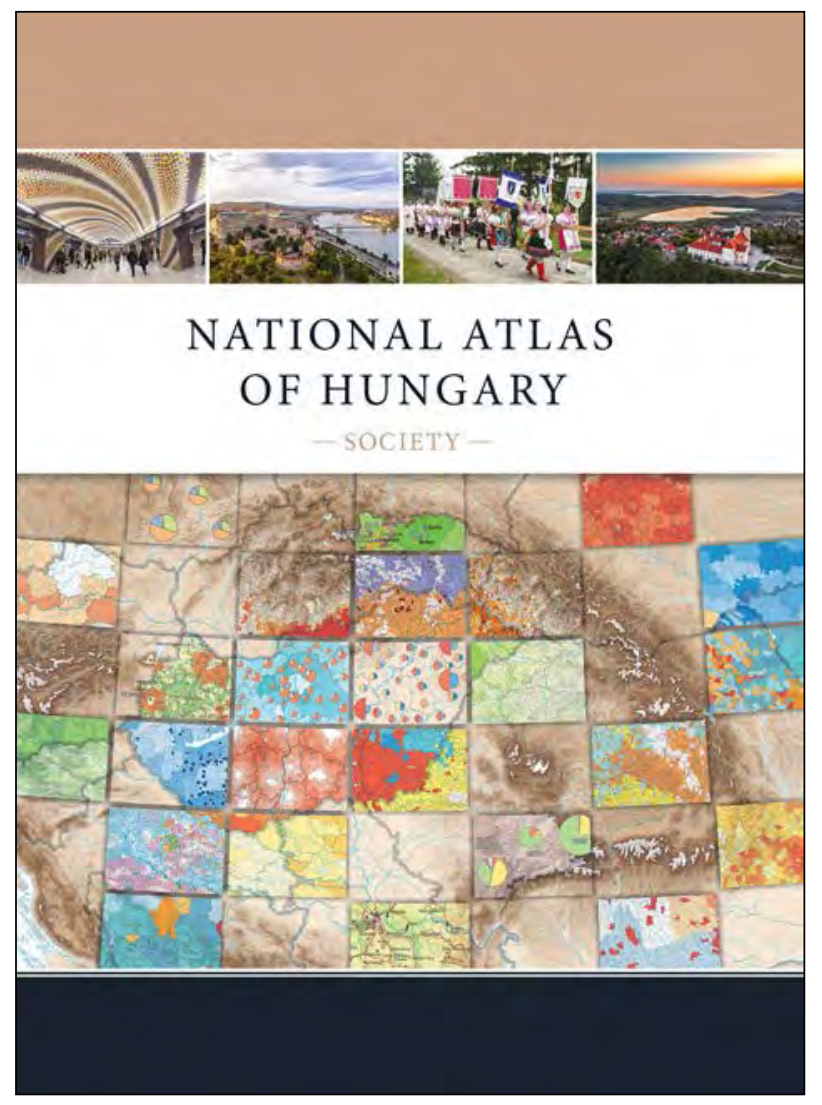

Figure 1. The cover page of the National Atlas of Hungary Society (size $31.0 \mathrm{~cm}$ x $42.5 \mathrm{~cm}$ ).

This volume of the National Atlas of Hungary is headed by an introduction to Hungary's society. It introduces the features of the past of population and settlements as well as spatial analyses of marital status, religion, social divisions, living conditions and the quality of life in Hungary, and whenever possible, in the Carpathian Basin (roughly from $44^{\circ}$ to $50^{\circ}$ North and $15^{\circ}$ to $27^{\circ}$ East) to highlight the spatial context of the themes. The equivalents of English geographical names as used in the country concerned are to be found in the List of English and Foreign Place Names at the end of the volume. 
The people of Hungary have shown their natural interest in the geography of the neighbouring countries for a century, because a major part of the Carpatho-Pannonian Area was included in the territory of the Kingdom of Hungary for one thousand years. This explains the new editorial policy for the National Atlas, owing to which there are several atlas maps in the twelve chapters and several subchapters that show and feature a much larger area (including parts of Central and Southeastern Europe) than just that of Hungary (within its historical borders, Figure 2) and national borders (Figures 3, 4 and 5).

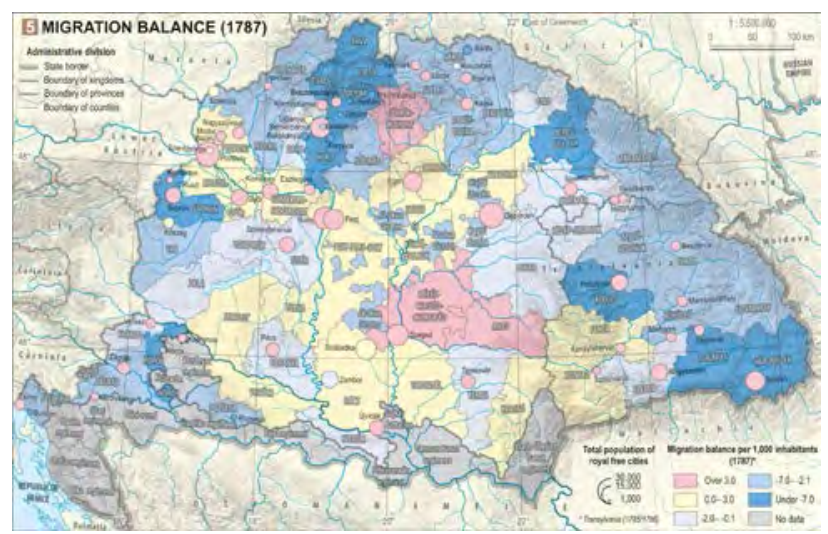

Figure 2. Migration balance (1787) (original scale $1: 5,500,000$, p. 17).

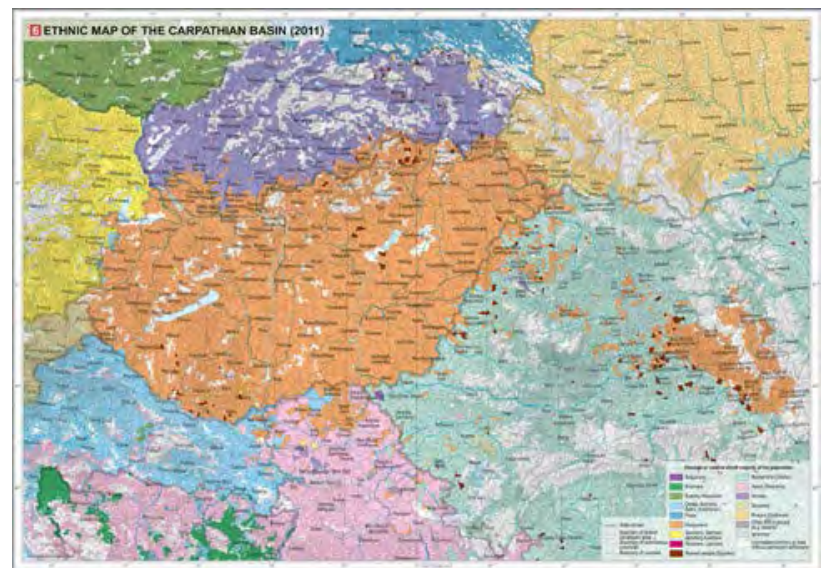

Figure 3. Ethnic map of the Carpathian Basin (2011) (original scale $1: 2,300,000$, p. 73 ).

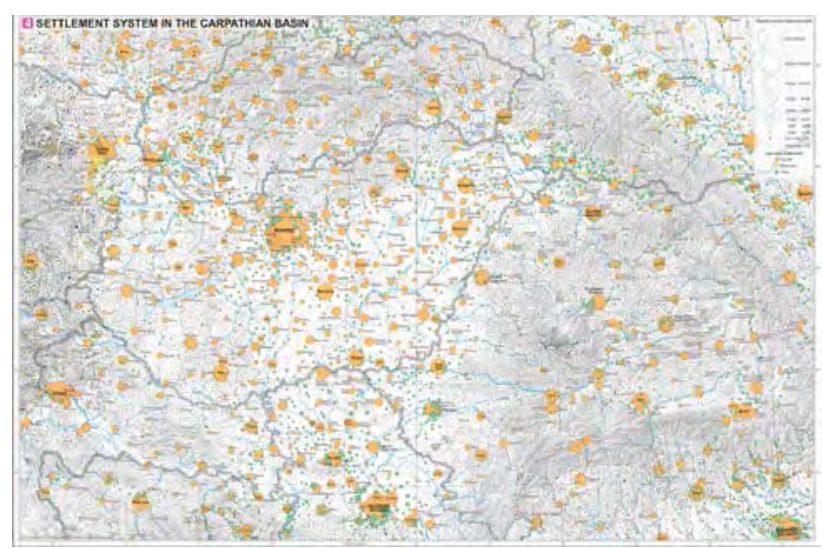

Figure 4. Settlements in the Carpathian Basin (original scale $1: 1,600,000$, pp. 110-111).

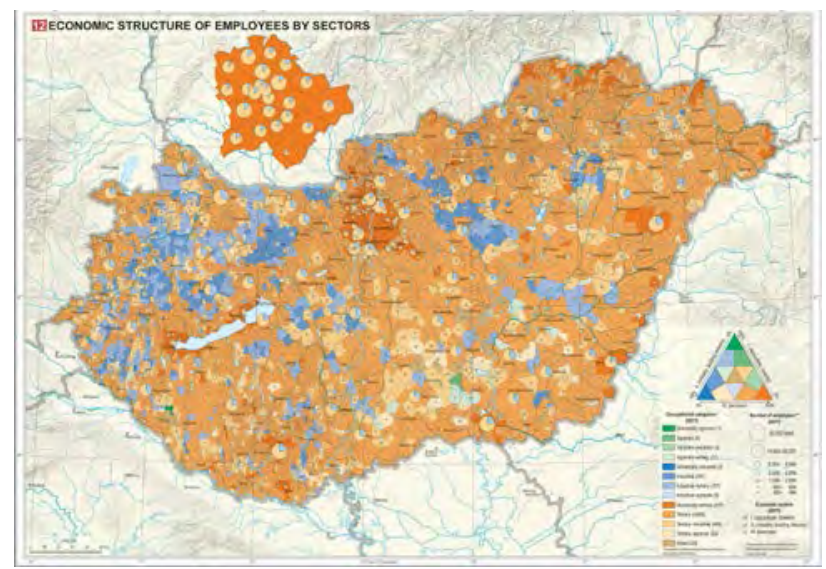

Figure 5. Economic structure of employees by sectors (original scale $1: 1,500,000$, p. 92).

This statement is true for the maps in all chapters. Therefore, this volume can also be considered as a kind of regional atlas that concentrates mainly on Hungary. This approach of the editors - without any irredentist overtone - will definitely help the international English speaking readers to see and interpret also the geopolitical position of a small country, Hungary in a broader (global) environment as well as recognize and understand the geographical unity of this region within Central Europe.

The Society, the second volume of the new version of MNA presents changes in the numbers of the population, its spatial distribution, vital statistics, migration and composition according to various aspects (e.g. sex, age, marital status, ethnicity, religion, education, employment, social stratification), the state and changes of the settlement system in relation to the area of Hungary (and to that of the Carpathian Basin). The synthesizing chapter on living conditions and quality of life is completely new compared to national and international antecedents. Compared to the chapters discussing Hungarian society in the 1989 version of MNA, in this atlas the volume of the material and the number of maps (scales mostly varying between $1: 1,500,000$ and $1: 6,000,000$ ) have increased four times and the ratio of explanatory text, figures, tables and pictures has increased from $25 \%$ to $50 \%$, whereby the inclusion of photos is a new feature in the Atlas. As a result of the new concept and available data, the number of maps showing the Carpathian Basin increased to 92, and their ratio regarding all maps increased to $30 \%$. Thematically, whereas demography and settlements dominated in the 1980s, the current atlas is far more balanced. New or more detailed elements include the presentation of the past of population and settlements as well as spatial analyses of marital status, religion, social divisions, living conditions and the quality of life.

Contrary to the traditional concept, this atlas provides much more than a collection of maps. Maps are dominant parts of the atlas, they catch the reader's eye, but detailed texts as explanations to the cartographic material constitute a much larger part of the volume than usual. The plenty of indicative photos also forms a crucial part of the project. This volume will surely shape the image of the country on the international scene since the atlas also appears in a global language. 


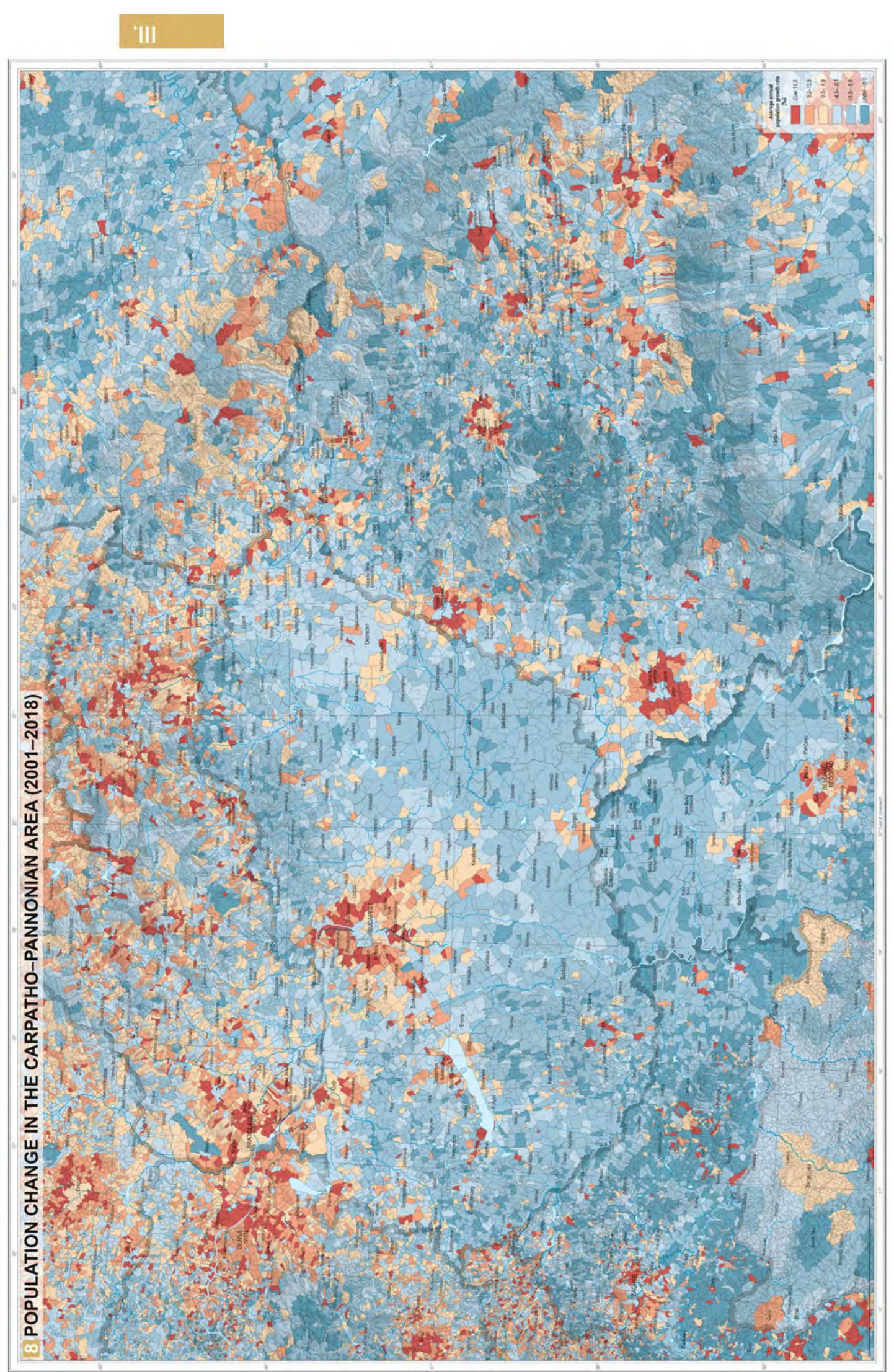

'II

Figure 6. Population change in the Carpatho-Pannonian Area (2001-2018) (original scale 1 : 1,600,000, pp. 26-27). 
In addition to the professional knowledge, enthusiasm, and data of the special strategic partner, the Hungarian Central Statistical Office, and the valuable contributions of the Hungarian Academy of Sciences and the Eötvös Loránd Research Network, the publication of the present volume of the new version of the National Atlas was made possible - in accordance with international practice - by support from the Government.

\section{Chapters in the Society atlas}

I. Hungary at a glance. This chapter offers a short introduction to Hungary's overall structure and situation on three pages, including a map of the country's administrative divisions as well as a two-page geographical map of the Carpatho-Pannonian Area with an impressive relief representation at $1: 1,800,000$.

II. History of population chapter introduces the settlement of the Hungarian people in the Carpathian Basin beginning in the late 9th century and the consolidation of the state until the Ottoman conquest (1526), which brought constant wars almost throughout the following two centuries. Maps and statistics illustrate the languages and population density of the time as well as the changes in the ethnic pattern due to the migration of the people within historic Hungary during war times and into the desolated parts of the country after the ending of wars. The demographic events between the 18th and early 20th centuries are richly illustrated by maps at $1: 5,500,000$ scale.

III. Population number, population density. The text part includes an analysis of changes in the population in three major periods between 1910 and today. Passages on the spatial distribution and density of population also look at the trends beginning in the mid-19th century and lasting in the 21st century. The chapter includes numerous maps, two tables and a graph on six pages out of ten. Hungary is shown at $1: 1,600,000$ to $1: 3,300,000$ maps, while the Carpatho-Pannonian Area at $1: 1,600,000$ to $1: 6,000,000$. The map, Population change in the Carpatho-Pannonian Area (2001-2018), with its content and careful execution is particularly impressive (Figure 6). IV. Natural change of population. This relatively long chapter on twelve pages is richly illustrated by graphs and pictures in addition to some twenty maps, half of which shows the thematic maps of Hungary, and another half covers the Carpatho-Pannonian Area. This greatly helps understanding and interpreting the past and the processes of Hungarian population changes. The study completed by various figures discusses topics such as the natural change of population in the last century; fertility trends; relationship changes in partnerships, life prospects in European context, causes of death and natural increase/decrease. Due to the character of the theme, several statistical terms are explained in boxes.

Migration is considered as the internal or international movement of people. The chapter $V$. Migration deals with these two aspects mainly focusing on the movement of Hungarians. It starts with the international migration in the Carpathian Basin and continues with examining Hungary in the currents of international migration since the end of World War I. An interesting section, including a map of Europe, makes us remember the Hungarians who moved abroad. As for internal migration, questions like suburbanisation, commuting and its spatial structure are described. This whole passage is enriched with several photographs of peoples and their environment that make the reader feel the subject closer to the mind.

VI. Population structures. This is by far the most voluminous chapter of all on forty-four pages. The editors of the Society atlas split the subject into seven subchapters each between four and eight pages. Altogether, they exactly come to one fourth of the atlas in the strict sense of the word. Here, only the title of the exciting subjects is listed: Sex and age; Marital status and households; Ethnicity, language; Religion; Educational structure; Economic activity; Social stratification. All these topics are profoundly treated with supporting statistical figures, graphs, photos and lots of maps, which set the Hungarian state of affairs also in regional context.

VII. History of settlement takes the reader back into history and how the past events and long-lasting processes are reflected in what we see today. This short chapter presents the textual description following the same division of periods as in chapter II. History of population. Six maps of historical Hungary (at maximum $1: 3,600,000$ ) cover the settlements from the late-11th century to the hierarchy of settlements in 1910. The most interesting figures are sample maps (fourteen in number) at topographic scale, which show expressively the development of different types of towns from various parts of the Carpathian Basin since the 16th century as well as the peculiar world of Hungarian farmsteads.

VIII. Settlement system. This chapter continues the former one with treating the massive changes in the settlement system in the Carpathian Basin after World War I. The settlement system of the Carpathian Basin is examined by population size, then followed by the settlement system of present-day Hungary. The text box containing six maps of settlements and two expressive pictures explains how the settlements with specific forms have developed in the Carpathian Basin over time. This is an exciting reading not only for geographers. The analysis of settlements in functional sense and the related maps are worth reading if someone is interested to understand the regional social differences that definitely exist in Hungary.

The chapter IX. Cities first offers an overview of the transformation of the urban system and changes of the rights and levels of towns in the Carpathian Basin from the Middle Ages until the collapse of communism in the region. The population dynamics of cities and towns show great differences in the area. The process that led to the present situation is illustrated by several maps, including the expansion of cities after the second half the 19th century. The second part of this chapter treats with the types of cities and towns developed in Hungary after World War II followed by presenting their dynamics and morphological characteristics (six maps). An interesting section discusses the distribution of some high-rank institutions in the Hungarian urban system. A section on agglomerations and creative towns finishes the chapter.

$X$. Budapest and its region. This chapter of the Atlas gives an excellent geographical-sociological overview of a modern world city, the capital of Hungary, on twelve pages. Pictures and the data in tables bring Budapest closer to the reader, while various thematic maps of the city and 
its neighbourhood show the geographical complexity of Budapest and its agglomeration. The following topics on the city and its agglomeration are detailed by text and supplemented by figures and maps, which often break down the information into the level of districts. These topics include the spatial structure; population (population number and density; age structure, household composition; ethnicity, religion; level of education, employment; social characteristics); housing market (age structure of the housing stock; housing tenure, number of rooms; housing conditions, residential mobility, urban renewal); Budapest agglomeration (historical development and spatial structure of the agglomeration; society in the agglomeration; housing market of the agglomeration).

XI. Rural areas. There are about 3,000 villages and farmsteads in Hungary today, but their traditional agricultural image has substantially changed over the past decades. This chapter presents this transformation as well as their varied character and their role in the economy. The villages are typified according to available services, their dynamics, functions and complexity. A short case study of two districts illustrates the service provision in areas with tiny villages. The section on rural landscapes ("village regions") is an interesting regional geographical classification of Hungary.

The long chapter XII. Living conditions, quality of life and its subchapters take twenty-six pages of the Atlas, which indicates that the editors thought it a challenging topic also for the scientists of tomorrow. The maps and other data give a balanced picture of the regional differences in the country in terms of living conditions and of how the people can get on in life. Among several others, such issues are presented in sections like Human side of living conditions and quality of life and Settlement side of living conditions and quality of life. This latter treats with the housing conditions and the municipal environment.

After a plenty of thematic information elaborated in the Atlas, the reader will find a detailed list of authors, bibliography and sources as well as of figures, tables and pictures. The final section of the Atlas is a long list, a kind of gazetteer of English and foreign place names occurring in the Atlas. Foreign readers interested in the geography of Hungary and the Carpatho-Pannonian Area will find this compilation most important.

\section{References}

Jordan, P. (2019). Kocsis, K., Gercsák, G., Horváth, G., Keresztesi, Z. and Nemerkényi, Z. (eds.): National Atlas of Hungary Vol. 2: Natural Environment. Book review in Hungarian Geographical Bulletin, 68/1. pp. 93-96. DOI: https://doi.org/10.15201/hungeobull.68.1.7

Kocsis, K., Nemerkényi, Zs., Zentai, L., Gercsák, G. (2019). The new National Atlas of Hungary - volume Natural Environment. Proceedings of the International Cartographic Association, 2, 64, Tokyo. DOI: https://www.proc-int-cartogr-assoc.net/2/64/2019/

https://icaci.org/map-awards/

http://www.nationalatlas.hu/ 